\title{
APPLICATION OF A METHODOLOGY FOR THE SPATIAL ANALYSIS OF AIR POLLUTANT LEVELS AT THE DARCY RIBEIRO CAMPUS OF THE UNIVERSITY OF BRASÍLIA
}

\author{
RODRIGO OLIVEIRA WERNECK \& FABIANA SERRA DE ARRUDA \\ Department of Civil and Environmental Engineering, University of Brasília, Brazil
}

\begin{abstract}
Transport modes, in particular those using fossil fuels, are considered to be responsible for atmospheric and noise pollution, causing damage to the landscape and environmental degradation. The cities growth, which is not always accompanied by significant investments in public mass transport, stimulates the expansion of individual transportation use. Some universities are beginning to investigate factors that may influence the more sustainable mobility on their campuses, thus promoting the improvement in quality of life and circulation. The Darcy Ribeiro Campus of the University of Brasília $(\mathrm{UnB})$ acts as a traffic generator pole, attracting a large number of automobiles that bring a series of negative consequences, such as congestion points, points of conflict with pedestrians and cyclists, depletion of public spaces and environmental impacts (air and noise pollution). Therefore, the objective of this project was to apply a methodology for the spatial analysis of the levels of atmospheric emission by the automotive vehicles in the Campus Darcy Ribeiro of the UnB. By means of vehicles volumetric counting, it was possible to generate carbon monoxide emission charts of the campus using Arcgis ${ }^{\mathbb{B}}$ software, identify critical points associated with air pollution and compare two scenarios, normal and optimistic. It was possible to conclude that, according to the estimates presented, the private transport in UnB is the largest source of air pollution. The figures presented, together with the charts generated, show that the vehicular pollution is present all over the campus perimeter and it represents a serious concern for the health of the university population. Some measures can be adopted to make the university a more sustainable environment regarding individual transportation, encouraging the use of active transport such as walking and pedaling and the use of public transport. Allying active transports with a well-designed transportation planning appropriate for the campus are factors that help the quality of life in college.
\end{abstract}

Keywords: transport modes, air and noise pollution, environmental impacts, spatial analysis, sustainable mobility.

\section{INTRODUCTION}

Transport modes, especially those using fossil fuels, are considered to be responsible for atmospheric and noise pollution, causing damage to the landscape and environmental degradation. The growth of cities is not always accompanied by significant investments in mass public transport; it stimulates the expansion of the use of individual transportation. Congestion, conflicts between the movement of pedestrians and vehicles, poor safety conditions of the fleet, risk of accidents, excessive emission of noise and gases, respiratory diseases, increased travel times, fuel consumption and deterioration of the architectural heritage are some of the most visible externalities resulting from an unbalanced transport matrix.

Heavy use of the car in urban traffic causes excessive dispersion and fragmentation of land use. In addition, the very high accessibility image that it offers, combined with the full urban insertion capacity of vehicles (although compromised in the big cities by congestion), 
still has a strong attraction on the users and gradually transforms the pedestrian circulation spaces and green living areas in potential parking lots.

In order to accommodate the entire fleet of vehicles in circulation, some measures taken (extension of the road system, destruction of green areas, etc.) were directed exclusively at meeting the needs of traffic, relegating environmental issues to less important plans, which contribute to the deterioration of the environment. The very high fleet of motor vehicles and the fact that the most consumed fuel is gasoline, lead mainly to the emission of high rates of carbon monoxide $(\mathrm{CO})$ and nitrous oxides $\left(\mathrm{NO}_{\mathrm{x}}\right)$ into the atmosphere. In the metropolitan area of São Paulo, in 2000, road traffic accounted for $98 \%$ of the carbon monoxide (CO) produced, CETESB [1], causing serious damage to the health of the population. The harmful effects of vehicular pollution are perceived by the population through cardiorespiratory and allergic diseases, cancer development and increased mortality rate due to respiratory problems. Among the pollutants coming from motor vehicles are particulate matter, sulfur monoxide and dioxide, carbon monoxide, carbon dioxide, hydrocarbons, and others, Saldiva $[2]$.

The negative impacts of the excess of automobiles in circulation in the big cities can also be observed nowadays in the Brazilian universities. Some of these universities are beginning to investigate factors that can influence the more sustainable mobility on their campuses, thus promoting improved quality of life and circulation. According to Ferreira and Silva [3], higher education institutions should lead education models that promote sustainability, and should serve as an example for society.

According to the Brazilian Institute for Transportation and Development Policy [4], sustainability in transportation is sought to achieve the collective well-being of the population. Factors like investing in sidewalks, bike lanes and express bus lines are exits to the current congestion. Align this with public policies aimed at those most in need and tailor public transport to them in the detriment of others. These factors will contribute to improve the quality of life of urban centers, such as in the city of Bogotá, in Colombia, and Buenos Aires, in Argentina.

The University of Brasília [5] currently has a university population of over 50,000 people, including teachers, students and technicians. On the Darcy Ribeiro campus, a large number of cars are causing a series of negative consequences, such as congestion points, points of conflict with pedestrians and cyclists, depletion of public spaces and environmental impacts (air pollution and noise). The excess of motor vehicles is due to several factors, such as ease of door-to-door transportation, comfort, safety and convenience, greater space-time mobility, irregularity of public transport and lack of adequate infrastructure for the use of non-motorized modes.

Many of the current car roads within the campus can be replaced by walking or bicycle use. This change would bring benefits not only to the people in the campus but to the environment as a whole. However, it is necessary to prioritize non-motorized modes of transport. Some measures could be constructing accessible and continuous sidewalks and bike paths, prioritizing them at intersections with automobiles, and restricting the use of the automobile in the campus.

Geographic Information Systems (GIS) can be used to identify and manage environmental information because they are appropriate tools for spatial analysis. With the use of GIS it is possible to locate spatially the effects of deformation, dispersion and effects of pollutant emissions in the urban environment. A set of studies that apply GIS as a tool for environmental analysis can be found in Taco [6]. This author has developed a methodology that allows the spatial identification of emission levels of gases derived from motor vehicles, with the help of GIS. According to the results, the author verified the applicability of the 
methodology in places where it is necessary to analyze the emission levels of carbon monoxide - $\mathrm{CO}$ and nitrous oxide - $\mathrm{NO}_{\mathrm{x}}$.

The area of study is a polygon delimited within the Campus Darcy Ribeiro of the University of Brasília. This area comprises the main pathways of the UnB, between collector and arterial ways. These roads are narrow, relatively flat, with level intersections and few parking lots, causing congestion at peak times. The main factors are the increase of the number of students of the UnB and the increase of the vehicular fleet of the Federal District, consequently increasing the fleet within the university. According to DETRAN-DF [7], the Federal District has a fleet of 1,650,259 vehicles in the statistics of July 2016. As a consequence of this fleet increase, there is congestion in the roads, besides the increasing atmospheric and noise pollution, influencing in the quality of life of all university students and employees.

In this context, it is important to identify the levels of vehicular pollution in the main roads of the Darcy Ribeiro campus. The identification of pollution on campus allows mitigation of adversities caused by motor vehicles. In addition, the results can be divulged to the society, showing the way that the individual and his vehicle pollute the atmosphere, so that one can evaluate his behavior when driving and be aware that the constant maintenance of the vehicle can improve the quality of the air he breathes, and consequently, his quality of life.

Thus, the objective of this project is to apply a methodology for spatial analysis of atmospheric emission levels by motor vehicles at the Darcy Ribeiro Campus of the University of Brasília.

\section{METHODOLOGY}

The methodology considers as main variables the flow of vehicles in roads and reference values of vehicular emission in Brazil (Filizola [8]). The methodology includes the generation of maps of emission levels of gases derived from automotive vehicles, using GIS.

- Step I: Delimitation of the study area.

- Step II: Survey of vehicle flow data.

- Step III: Assembly of the geographic database.

- Step IV: Determination of vehicle emission.

- Step V: Spatial representation of vehicle emission levels.

\subsection{Step I: Delimitation of the study area}

At this stage, the study area was delimited and characterized, Fig. 1. Consideration was given to the location and characteristics of the University of Brasília (planning, spatial configuration, land distribution, roads, cycle ways and sidewalks, bus stops) in order to identify and determine the extent of the vehicular pollution problem.

The counting points were distributed within the study area, encompassing all vehicular circulation routes. The points served both for geographic information and quantitative data for the volumetric determination.

\subsection{Step II: Survey of vehicle flow data}

For the accomplishment of this study, data of the flow of vehicles of 10 points of manual volumetric counting, located in the road network of the UnB were collected. Fig. 1 shows the spatial distribution of these counting points. 

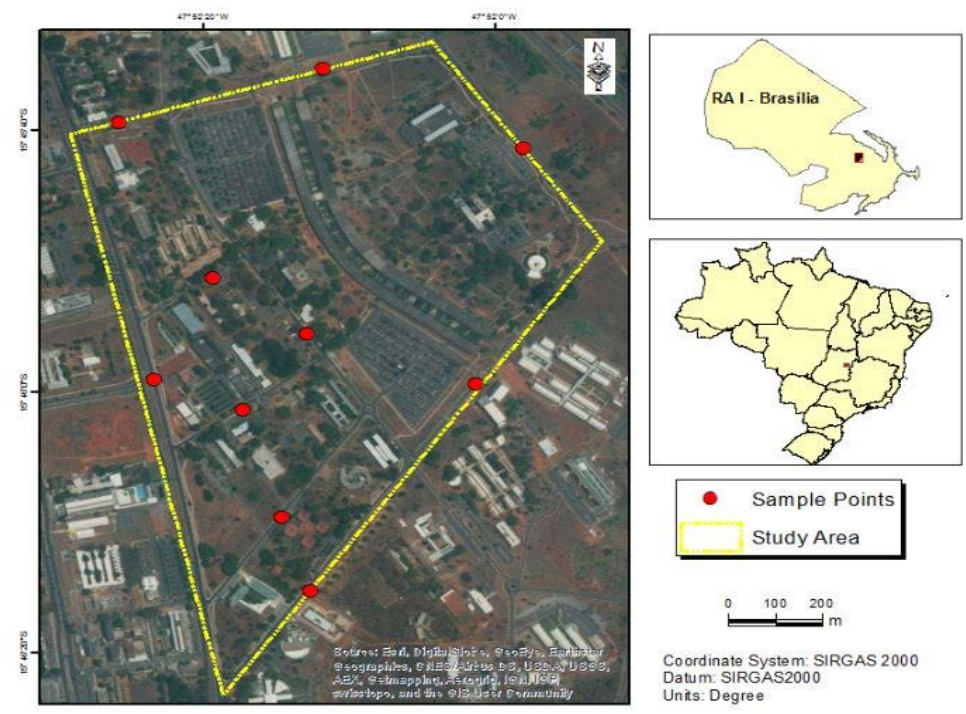

Figure 1: Spatial distribution of the volumetric counting points in the study area at UnB.

To obtain a flow of vehicles on the roads, a data collection was necessary. In the case of $\mathrm{UnB}$, the data were collected using the 15-minute manual volumetric count at peak hours of the morning from 07:00 a.m. to 08:30 a.m., and from 5:00 p.m. to 6:30 p.m., during the days 22/03, 23/03, 24/03, 10/05 and 12/05, 2016.

According to Akishino [9], the recommendations for the method are described below. Manual Volumetric Counting: used in specific places, where the desired data cannot be obtained by mechanical counts. In the case of small volumes, the simple marking in appropriate forms is enough; for small volumes, small devices with easy manual operation can be used.

It is proposed in the methodology, the accomplishment of the manual count for the study of the vehicular emission in the routes for short time, aiming, mainly, the peak times. For the creation of the atmospheric pollution scenario, we considered the mean of the vehicular flow of the two peak times.

\subsection{Step III: Assembly of the geographic database}

This step aims to compose the geographic database, considering the data collected in the previous stage. The process followed was due to the way the data were collected and organized for the study of emissions.

The database of vehicle flows was prepared in worksheets of Microsoft Excel (* .xls), because this software allows to work with files of type Database (* .dbf), also allowing its integration with the GIS software used in the work - ArcMap ${ }^{\circledR} 10.4$.

Volumetric counting data were defined in two vehicle categories, light (car,motorcycle) and heavy (bus, truck) in order to obtain the total number of vehicles in the gasoline category. When the category under study was estimated, the database was elaborated. The information of each counting point had the following attributes: the location of the meter, the number of vehicles and the category according to the type of fuel. 
The geographic base is constituted by the road network of the University of Brasília, delimiting a polygon of study, where the points of counting of vehicular flows were georeferenced. The image base is that of the software itself and are images provided by GoogleMaps ${ }^{\circledR}$.

The geographic database was composed of the crossing of the database of flows of vehicles and the geographic base. By means of the projection and overlapping of the information chosen on the geographic basis, by applying an IDW type interpolation in the software, two scenarios, normal and optimistic, were elaborated to analyze the vehicular pollution within the Campus Darcy Ribeiro. ArcMap ${ }^{\circledR}$ software was used to work with the geographic base.

The SIG ArcMap ${ }^{\circledR}$ version 10.4 according to ESRI [10] was chosen to integrate the data, since the software allows the manipulation of several vectors and raster-type data, using cartographic bases already implemented in the system. The use of this GIS allowed an easy integration with the digital base of the map and the results of the calculations of the Excel worksheet, allowing the creation of scenarios of vehicular pollution.

At each counting point, the information carries on location, track, vehicle flow at peak time, emission level for $\mathrm{CO}$ and $\mathrm{NO}_{\mathrm{x}}$, different hours of study and emission factors for each pollutant.

\subsection{Step IV: Determination of vehicle emission}

In this stage, the vehicle emission was determined according to the characterization of the vehicular flow, the vehicle fleet and the emission factors $\left(\mathrm{CO}\right.$ and $\left.\mathrm{NO}_{\mathrm{x}}\right)$. The calculations were based on the formulas presented in the proposed methodology. The values obtained are expressed in grams per hour per kilometer of route. The emission factor used for each pollutant represents the normal traffic conditions, where the average emission indices obtained during the tests were used to compose the scenarios that would represent a large part of the national fleet, as determined by Filizola [8], thus, it can be applied to any Brazilian city.

The emission quantification was calculated by applying the equation established in the proposed methodology. As an example, the $\mathrm{CO}$ emission calculation is shown at the $\mathrm{P} 1$ counting point, Fig. 1. In the equation, FEi represents the emission factor (grams / kilometer) of the pollutant $\mathrm{i}$ and $\mathrm{Njt}$ is the flow of vehicles in the track or counting point $\mathrm{j}$, in a period of time $t$ expressed in vehicle / hour. Eijt is the emitted amount of the pollutant $i$, during the period of time t of study of a certain route $j$.

$$
\text { Eijt }=\text { FEix Njt, }
$$

where:

Eijt $=$ Echo $(\mathrm{P} 1)(7 \mathrm{~h})$

$=\mathrm{CO}$ emission at the $\mathrm{P} 1$ counting point at peak time 7 a.m. -8 a.m.

$\mathrm{FEco}=\mathrm{CO}$ emission factor $=2.0 \mathrm{~g} / \mathrm{Km}$

$\mathrm{Nij}=$ Vehicular volume at the point of counting P1 at peak time 7a.m.-8a.m.

$=1,201$ vehicle/hour

Applying the eqn (1) we have the result of the emission of $\mathrm{CO}$ in the P1 at 7a.m.-8a.m.: Eco $(\mathrm{P} 1)(7 \mathrm{~h})=2.0 \times 1201=2,402$ grams/hour/kilometer

It should be noted that the emission calculation was performed for each counting point (manual volumetric count) under study, for $\mathrm{CO}$ and $\mathrm{NO}_{\mathrm{x}}$ the same formula was applied. 


\subsection{Step V: Spatial representation of emission levels}

For the spatial representation of $\mathrm{CO}$ and $\mathrm{NO}_{\mathrm{x}}$ emission levels, counting points are considered as emission points. As the University of Brasília presents many public spaces that do not have roads, it was necessary to perform an IDW interpolation of the data to cover the places where it was not possible to count.

The IDW interpolation is an interpolation method that estimates the cell values by analyzing the mean values of each cell in its vicinity that were quantified. The closer a cell is to the center of the cell being estimated, the greater the influence, or weight, it will have in the process of measuring its value.

Once the geographic database has been constructed and the vehicle emission levels values calculated it must be represented spatially. After defining the mode of spatial representation of vehicular emissions, emission scenarios are created, representing the various variable study conditions (time, velocity, fuel type, dispersion of pollutants, etc.). The scenarios created for the study pollutants $\left(\mathrm{CO}\right.$ and $\left.\mathrm{NO}_{\mathrm{x}}\right)$ were the normal scenario and the optimistic scenario.

\section{RESULTS AND DISCUSSION}

With the methodology proposed by Taco [6] and its implementation in the study area of the Darcy Ribeiro campus of the University of Brasília it was possible to carry out vehicular pollution maps, Fig. 2(a), (b) and Fig. 3(a), (b). The application of the methodology made possible the spatial analysis of the pollutant carbon monoxide (CO), one of the main responsible for harmful effects to the human health. The spatial representation of vehicle emission levels made it possible to visually identify CO hot spots in UnB. In this way, it was identified that the route containing the Petrobras gas station, the Black Cohabitation Center and the Indigenous Maloca (point 1) and L3 North road (point 3) present maximum levels of $\mathrm{CO}$ and $\mathrm{NO}_{\mathrm{x}}$ emission (point $1-3,107.81 \mathrm{~g} / \mathrm{km} / \mathrm{h}$ at normal scenario), compared to other roads that make up the road system of the University of Brasília. This is due to the high volume of vehicles in these routes, with more than 1500 vehicles/hour at peak times, produced by the movement of the population of the administrative regions to the city center, especially to the University of Brasília. The high volume of vehicles in these routes can generate a slower average speed, causing congestion, and, therefore, higher levels of vehicular pollution.

Table 1: Scenarios proposed by Filizola [8] for emission of carbon monoxide (CO) and nitrous oxide $\left(\mathrm{NO}_{\mathrm{x}}\right)$. Adapted from Table 5.4 of Taco [6].

\begin{tabular}{|l|l|l|l|l|l|}
\hline \multirow{2}{*}{ Scenarios } & \multicolumn{2}{|l|}{ Scenario characteristics } & \multicolumn{2}{|l|}{$\begin{array}{l}\text { Filizola } \\
\text { emission factor } \\
(2005)(\mathrm{g} / \mathrm{km})\end{array}$} \\
\cline { 2 - 6 } & Age of the fleet & $\begin{array}{l}\text { Driving } \\
\text { mode }\end{array}$ & $\begin{array}{l}\text { Catalyst } \\
\text { functionality }\end{array}$ & $\mathrm{CO}$ & $\mathrm{NO}_{\mathrm{x}}$ \\
\hline $\begin{array}{l}\text { Pessimistic } \\
\text { scenario }\end{array}$ & Old & Aggressive & $\begin{array}{l}\text { Old catalytic } \\
\text { converter }\end{array}$ & 2.83 & 0.32 \\
\hline $\begin{array}{l}\text { Normal } \\
\text { scenario }\end{array}$ & Intermediary & Normal & $\begin{array}{l}\text { Modified } \\
\text { catalyst }\end{array}$ & 2.00 & 0.21 \\
\hline $\begin{array}{l}\text { Optimistic } \\
\text { scenario }\end{array}$ & New & Defensive & $\begin{array}{l}\text { New catalytic } \\
\text { converter }\end{array}$ & 1.16 & 0.10 \\
\hline
\end{tabular}

Created the scenarios, it is possible to identify critical emission levels of the pollutants under study. 
The elaboration of the normal and optimistic scenarios, Fig. 2(a), (b) and Fig. 3(a), (b), respectively, was through the same database of vehicle volumetric counting. However, each scenario had a different weight, according to the Table 1.
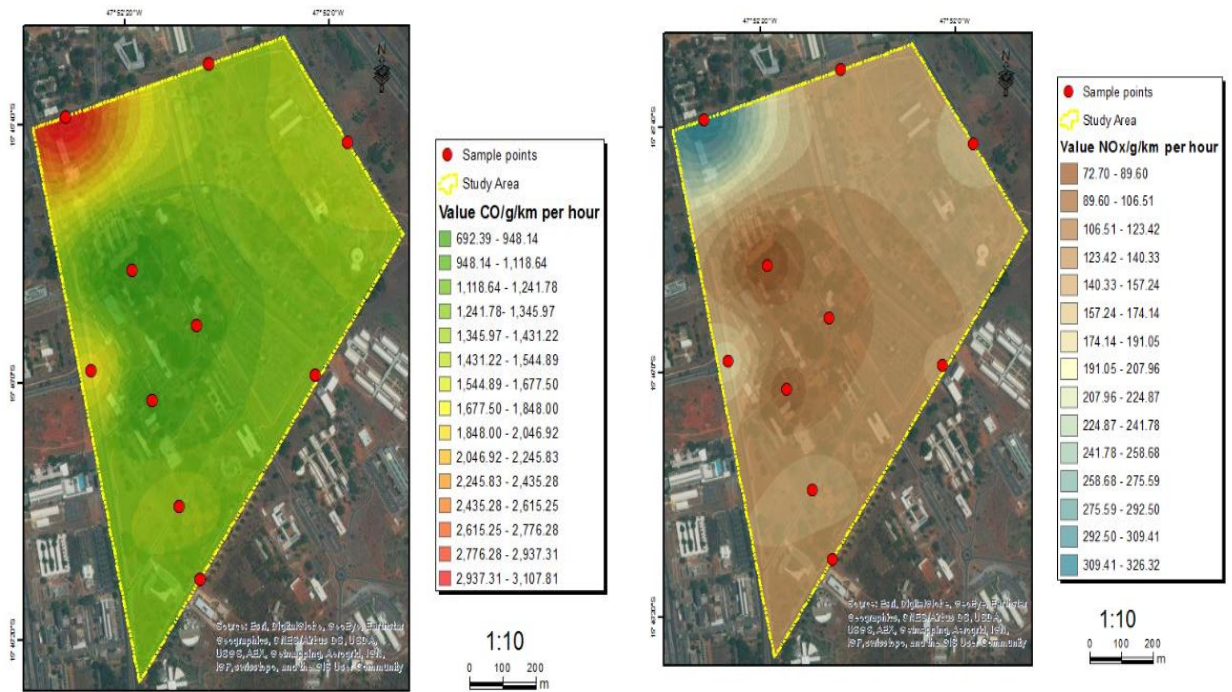

Figure 2: (a) Vehicle pollution map in $\mathrm{CO} \mathrm{g} / \mathrm{km} /$ hour - Normal scenario; (b) Vehicle pollution map in NOx g / km / hour - Normal scenario.
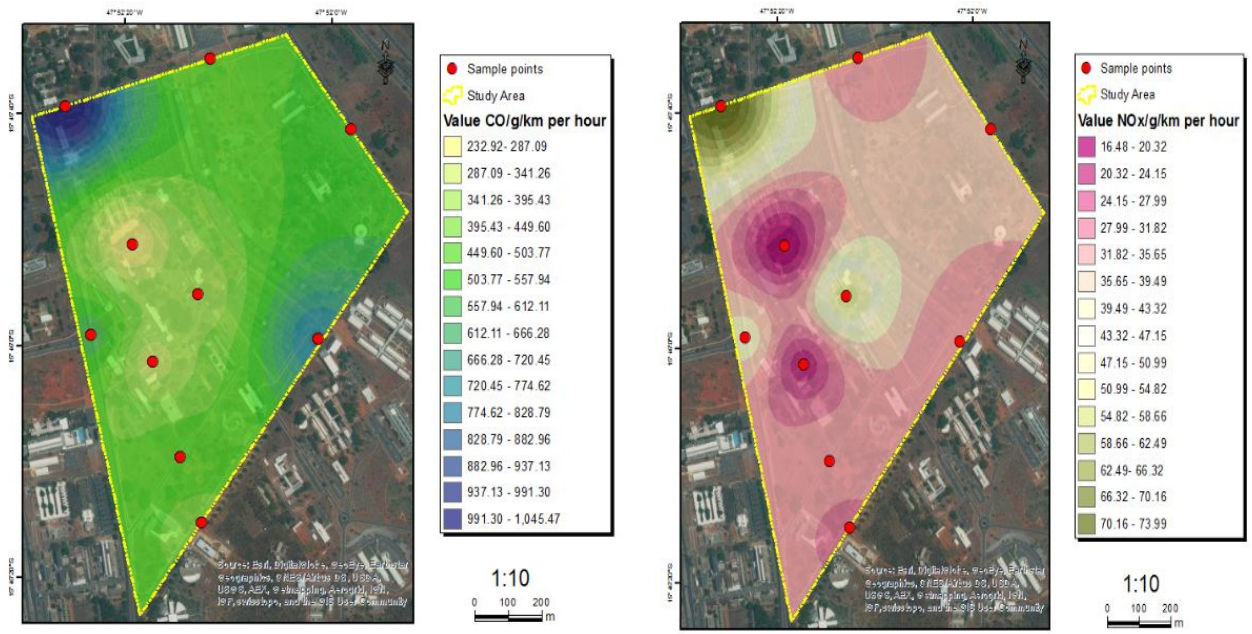

Figure 3: (a) Vehicle pollution map in $\mathrm{CO} g$ / km / hour - Optimistic scenario; (b) Vehicle pollution map in NOx g / km / hour - Optimistic scenario. 
The optimistic scenario allowed visualization of the reduction of carbon monoxide and nitrogen oxide emission within the UnB in comparison to the normal scenario. The optimistic scenario represents a set of pro-mobility actions within the Darcy Ribeiro campus: connect, compact, transit, densifying, shift, mix, cycle and walk, ITDP Brazil [4]. Such actions would bring to the campus a more diversified urban mobility.

Fig. 4 shows the 8 principles for better streets and better cities, ITDP [4]. Walk: develop neighborhoods that promote walking; Cycle: prioritize non-motorized transport networks; Connect: create dense networks of streets and paths; Transit: locate development near high-quality public transport; Mix: plan for mixed use; Densify: optimize density and transit capacity; Compact: create regions with short commutes; Shift: increase mobility by regulating parking and road use. Applying these principles to the transport planning brings benefits to the entire academic community. In order to achieve this objective, it is necessary to carry out several measures that favor collective and non-motorized individual transportation.

It is believed that the application and updating of the proposed methodology will contribute to the better planning and management of mobility in the university, aiming at improving the quality of life of all university community.

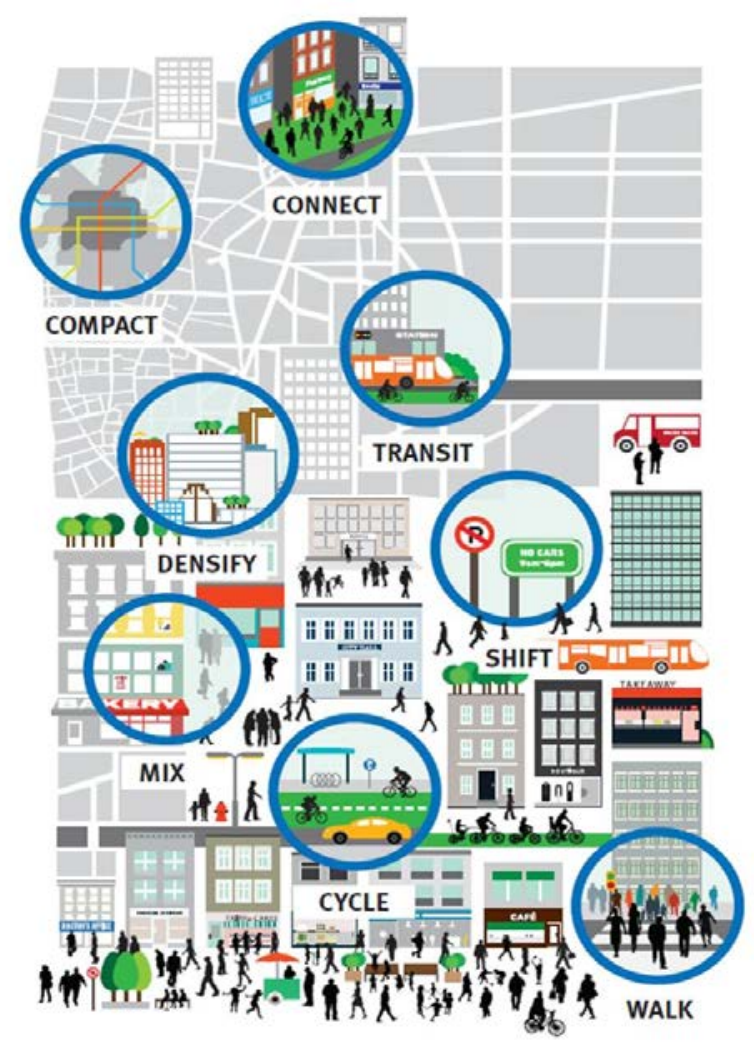

Figure 4: The 8 principles for better streets and better cities. Optimistic scenario. ITDP Brazil [4]. 


\section{CONCLUSIONS}

For the development of the present study, it was extremely relevant to understand the origins of the pollutant emissions and their adverse effects, mainly on the health of the population, causing diseases such as: allergies, cardiovascular diseases, cancer and respiratory problems. In this way, it becomes necessary to know, through quality control, how much the air is polluted. Such understanding is important in defining efficient air quality improvement strategies on campus.

In this paper, it has been widely shown that air pollution is the main environmental impact generated by the increase in automobiles in circulation. It has also been shown that, in general, control measures are based on the development and establishment of air quality standards and vehicle emission standards, in order to establish limits that contribute to the reduction of pollutant emissions.

Sustainable alternatives to mitigate vehicular pollution range from the prohibition of flow of vehicles on some roads of the university, such as the case of the Faculty of Education, which prohibited the traffic of vehicles to make the road a recreation and cultural area, passing by the possibility of prioritizing active transport, building cycle paths and sidewalks, instead of building more roads for cars. Reaching the point of restructuring the master plan for transportation on campus, aimed at reducing the high levels of pollution of the gases emitted by motor vehicles.

Many of these solutions have been drawn from the Institute for Transportation and Development Policy [4], which presents sustainable solutions for large metropolis, which also apply to the situation of the University of Brasília, in order to reduce inequalities, promote accessibility to services, improve and promote sustainable development and strengthen public institutions.

It is possible to conclude that, according to the estimates presented, private transport in $\mathrm{UnB}$ is the largest source of air pollutants. The figures presented together with the charts generated, show that vehicular pollution is present all over the campus perimeter and represents a serious concern for the health of the university population.

\subsection{Limitations of the study}

There were some limitations of the study when applying the methodology in the case study. Initially, it should be emphasized that the sample of the volumetric counting points: 10 points - was not statistically significant, fomenting restricted inferences about the objectives that it was proposed to achieve. In addition, information about active transport (walk and cycle) was not counted at all points, they were disregarded to avoid errors in the emission calculations.

Another aspect that should be emphasized is the lack of data regarding the measured speed of the vehicles, which made it impossible to evaluate the influence of this variable on the emission of the pollutants.

\subsection{Future perspectives}

In future work, development of scenarios of air pollutants emissions based on substitution of vehicles that circulate through the university by more sustainable modes (walking and cycling) and by electric powered buses can be performed. Besides, the study should cover wider contexts, like the main highways in the road network of the Federal District, reaching a greater number of people affected by the automotive pollution. The maps generated and the quantitative emission values found for the current numbers of the Brasília fleet will allow the 
comparison of these data with the measures to control vehicle emissions developed by the Air Pollution Control Program for Automotive Vehicles- PROCONVE [11] and with the quality standards that were established in CONAMA Resolution number 03/1990 [12].

\section{REFERENCES}

[1] CETESB - Environmental Sanitation Technology Company. Air Quality Report for the State of São Paulo 2000. Sao Paulo, 2001.

[2] Saldiva, P.H.N., Pereira, L.A.A. \& Braga, A., Atmospheric pollution and its effects on human health. Faculty of Medicine, Sao Paulo, 1995.

[3] Ferreira, D.I.R. \& Silva, J.P.C., Contributions of the management of the mobility in the change of mentalities: The case of the Polytechnic Institute of Leiria. Transportation Magazine, 20(3), 2012.

[4] Brazilian Institute of Transportation and Development Policies (ITDP BRAZIL). Quality standard Transit Oriented Development (TOD). Online. http://itdpbrasil.org.br/padrao-de-qualidade-tod. Accessed on: 19 Mar. 2017.

[5] University of Brasília. Management Report for the financial year 2016. Online. http://www.dpo.unb.br/index.php?option=com_phocadownload\&view=category\&id $=1 \&$ Itemid $=675$. Accessed on: 2 Apr. 2017.

[6] Taco, G.B.G., Development of a methodology to identify spatially the emission levels of gases derived from motor vehicles in urban areas. Master's dissertation in Transport, University of Brasília, 2006.

[7] Brazil. Department of Transit of the Federal District - DETRAN DF. Traffic statistics: fleet of vehicles, fleet bulletin, July 2016. Online. http://www.detran.df.gov.br/odetran/estatisticas-do-transito/frota-de-veiculos.html. Accessed on: 19 Mar. 2017.

[8] Filizola, I.M., Identification of reference values of the level of emission of gases of light automotive vehicles of the Cycle Otto, Master's dissertation, University of Brasília, 2005.

[9] Akishino, P., Handles traffic studies, Federal University of Paraná, 2006.

[10] Desktop, ESRI-USA. ArcGIS. Release 10.4. Redlands, CA: Environmental Systems Research Institute, 2011.

[11] Brazil. PROCONVE - Program for Control of Air Pollution by Automotive Vehicles. MMA, 2001. Online. http://www.mma.gov.br/port/conama/res/res86/ res1886.html. Accessed on: 19 Mar. 2017.

[12] Brazil. CONAMA, Resolution. 03/1990. Online. http://www.mma.gov.br/port/ conama/res/res90/res0390.html. Accessed on: 19 Mar. 2017. 